\title{
Knowledge Organization in Information and Communication Sciences, a French Exception?
}

\author{
Viviane Couzinet \\ Université Toulouse III Paul Sabatier, LERASS-MICS, 115 B, Route de Narbonne, \\ BP 67 701, 31004 Toulouse cedex France, <viviane.couzinet@iut-tlse3.fr>
}

\begin{abstract}
Viviane Couzinet is Professor of information and communication sciences in the University of Toulouse III Paul Sabatier (France) and is former President of the National Council of the Universities for Information Communication Sciences (2004-2007). She has been Director of the Laboratory of Studies and Researches in Social Science (LERASS) for nine years. She is head of a research group called Mediation in Specialized Information-Communication (MICS) since 1997. Her research interests are related to Scientific Communication, especially between librarians and LIS researchers, KO and the concept of "document."
\end{abstract}

Couzinet, Viviane. Knowledge Organization in Information and Communication Sciences, a French Exception? Knowledge Organization. 39(4), 259-267. 19 references.

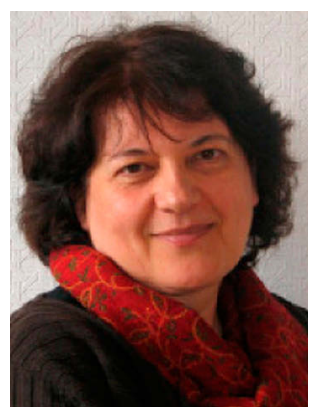

ABSTRACT: The alliance between information and communication sciences is a French specificity that originated in the 1970s from the necessity of assembling a sufficient number of researchers in order to obtain institutional recognition. The theme of knowledge organization brings a reflexive view on a discipline under construction. Our position in this article is to try, through a review of works conducted by the discipline's pioneers, to perceive how they envisioned the link between information and communication through the proposals made to their research community. French researchers approach the theme of knowledge organization in a way that does not seem very different from foreign research. As in foreign research, technique and technologies play significant roles. The ISKO conferences are, in this respect, very important. Knowledge organization also suffers from its interdisciplinarity, which deprives it of methodologies, theories, and concepts of its own. Its position at the heart of a discipline that is, itself, an interdiscipline, seems to authorize it not to consider its own fundamentals together with common theoretical foundations.

Received 7 March 2012; Accepted 7 March 2012

\subsection{Introduction}

It is often admitted that the alliance between information and communication sciences is a French specificity. This alliance would have originated in the 1970 s from the necessity of assembling a sufficient number of researchers in order to obtain institutional recognition. If, in this respect, the scientific value of such an alliance could appear limited, the researchers considered as pioneers of this discipline, known first under the code "section 32" and currently under "section 71," have been working on highlighting the strong links that unite these two disciplines.

The theme of knowledge organization, probably because it brings a reflexive view on a discipline under construction that was seeking academic recognition, was a main preoccupation of its founders for over ten years. Progressively, with technical matters prevailing over fundamental research and the institutionalization of the discipline considered acquired, French researchers were less bothered by their inscription in a field that had been identified as being an interdiscipline. However, participation in a research field whose recognition might be constantly challenged by reorganizations imposed by the authorities relies on the collective elaboration of a common scientific project. Recent works have been following this process.

On the other hand, everyday it becomes less possible to consider science in relation to administrative or political frontiers that delimit its perimeter, methodologies, objects, concepts, and approaches. Thus, joining a position or founding an international trend en- 
hances the debate and favors the progress of knowledge. Our position in this article is to try, through a review of works conducted by the discipline's pioneers, to perceive how they envisioned the link between information and communication through the proposals made to their research community. Following the way this link is analyzed nowadays and recontextualizing it in an international context, we will try to answer the following question: is there really a French exception in the way to conduct research on knowledge organization?

\subsection{The elaboration of a link between information and communication sciences}

\subsection{Information and communication sciences}

The definition of what the term "information and communication sciences" (ICS) covers has been the subject of the first publications of our discipline's founders. Among them, Robert Escarpit and Jean Meyriat worked specifically on the way this discipline approaches its objects of study in order to distinguish it from other disciplines, the second focusing on matters that were then in the field of information sciences.

Having delivered, during the first Sofras ${ }^{1}$ congress in 1978, a definition of the notion of document that he would refine in 1981, Jean Meyriat associates information to the material object that supports it in order to communicate its substance and that cannot be separated from it. He opposes it to information processed by computer specialists, for whom information does not make sense and is limited to a combination of signals (Meyriat 1980). He also establishes a link with the notion of communication, a mental relation process used to pool it together with psychological, sociological, political, economic, and legal dimensions which explain why it is studied in all humanities and social sciences. What differentiates ICS from other sciences is that it involves the study of the communication process, its contents, and "the means it employs and the mechanisms that make it work" (Meyriat 1983, 82).

Communication implies assigning a meaning. It is generated through a set of elements. It proceeds from the relation established with other elements that generate a form with it. The role of the subject is perceived as essential, thus there is no information per se. The tight link between information and knowledge is perceptible through the shaping activity implied by the passing from one to the other. Information becomes knowledge when it is activated by the recipient in the interaction, who then integrates and assimilates it into his own stock of knowledge. This activation depends on its informative significance, on the individual or collective interpretation capacity, and on the situation in which it is taking place.

The connection between these two notions can be made clear. The term information refers to cognitive content and to "knowledge transmitted and acquired and that builds knowledge items." The information that is the object of ICS work is then "knowledge either communicated or communicable" (Meyriat in Couzinet 2001, 251). It is then of "sustainable utility." Jean Meyriat defines it as received knowledge which "is added to other knowledge that had been preserved and whose structured compound elements constitute knowledge that is enriched cumulatively" (Meyriat in Couzinet 2001, 151). It lends a capacity to act, and he describes it as "scientific" in the most general sense of the word. Its utility makes it essential and imposes its conservation, from which derives its very tight link with document and document memory, a secondary information device that implies a specific organization.

\subsection{Knowledge organization: Jean Meyriat's contribution}

The first part of the research conducted by Meyriat on knowledge organization takes place in an international context. Involved since the beginning of the 1950 s in a group of UNESCO experts, he set up a committee of social sciences experts. In 1980, he conducted a comparative analysis of over 50 information languages, defined as "linguistic tools used to describe specialized information and hence for analyzing and indexing documents, for storing and retrieving information, for building classified files and for operating documentation systems" (Meyriat 1980, 60). This research is part of a programme aimed at establishing a common language specific to these disciplines to ensure compatibility between indexing systems and thus improve international scientific cooperation in the field.

The corpus was made of languages that came from researchers' projects or with a more operational status and an information retrieval function. These were either specialized or more general tools used to set up catalogues or thematic databases in the concerned disciplines. The first step in this research consisted of defining the fields covered by social sciences and then determining the number of descriptors that represented them in each language. The third step was a fine analysis of their semantic environment. It allowed 
V. Couzinet. Knowledge Organization in Information and Communication Sciences, a French Exception?

the author to highlight the elements that should be taken into account in the elaboration of what could be called an information language with a certain universal scope (Meyriat 1980), which would facilitate the exchange of research work.

Another matter of interest to the present conference is the epistemological work realized on the discipline through the organization of the objects covered by the field of ICS. Within a working group called "Communication means and contents" that he directed, Meyriat elaborated a classification of ICS. After renewed calls in various forms and articles submitted for review to members of the ICS scientific society or invitations to discussions at conferences-and that seem, as far as we know, to have received very few answers-the circumstances motivated him to establish the basis of a disciplinary territory. The Department of National Education had divided the discipline into five sub-domains in 1983documentation, archives, information, communication, and community based activity-for which teaching and training should prepare. To this division based on professions, Meyriat proposes one based on epistemology. He thus defines four classes that include various branches of SIC.

\begin{tabular}{|l|l|}
\hline \multicolumn{1}{|l|}{ 1.0.0 Communicology } \\
\hline & 1.1 .0 Medialogy \\
\hline & 1.1.1 Bibliology \\
\hline & 1.1.2 Iconology \\
\hline & 1.1.3 Cinematology \\
\hline & 1.1.4 Documentology \\
\hline & 1.1.5 Press studies \\
\hline & 1.1.6. Mass communication \\
\hline & 1.3.0 Informatology \\
\hline & 1.3.1 Persuasive communication \\
\hline & 1.3.2 Didactic communication \\
\hline & 1.3.3 Artistic communication \\
\hline & 1.3.4 Scientific communication \\
\hline & 1.3.5 Socio-cultural communication \\
\hline 2.0.0 Communication technology \\
\hline 3.0.0 Social Sciences of Information \\
\hline & 3.0.1 Information economics \\
\hline & 3.0.2 Political Science of Information \\
\hline & 3.0.3 Psychology of Information \\
\hline & 3.0.4 etc. Law, History, Geography, Sociology \\
\hline 4.0.0 Connected Sciences \\
\hline & 4.1.0 Formal Sciences \\
\hline & 4.2.0 Tool oriented Sciences \\
\hline
\end{tabular}

Figure 1. Classification of Information and Communication Sciences. Hierarchical representation established from (Meyriat 1983).
In this classification, we can observe that the set of objects or sciences included in what is generally called information science is quite obviously seen in three subdivisions (communicology includes medialogy, which, in turn, includes bibliology, iconology, and documentology; informatology, communication technology, and social sciences of information clearly appear to belong to information sciences). However, a more careful reading of this classification allows us to perceive the interweaving between information and communication sciences. We can, in fact, easily consider, without seeming animated by any hegemonic intention, that some aspects of cinematology, mass communication, and functional communication also report to information science.

This work aimed at ordering the fields of our discipline shows the extent to which this order can sustain and even serve an epistemological reflection. The classification of ICS aims at building a common cultural context that expresses an identity capable of differentiating them from other academic disciplines. The preoccupation is info-communicational. It proposes an organized and visible content that aims at mobilizing and creating a feeling of belonging to a single family. This first proposal will be used by the National Council of Universities, the authority that manages the careers of French professors-researchers, to define the skill domains of this discipline. Established under the presidency of Meyriat in 1984 and transformed into a set of objectives and approaches, they have been regularly updated and are still in effect today.

\subsection{Knowledge organization and scientific communication}

There are then two ways of approaching knowledge organization. One is driven by the harmonization and building of a language, from content analysis and the determination of its structural characteristics. The object of the study is the meaning built by source languages in order to provide means to process information, to index it, and to make it retrievable. We could say that the operational scope of this work is the result of a will to contribute to the improvement of scientific communication. The other is based on an intention to make visible and to define a collective project included in a "territory." Its political aim is to establish its positioning as a science. The object is not indexing anymore, but it is still scientific communication.

Manifesting an interest for "communicable or communicated knowledge," "useful and sustainable," 
with the aim of facilitating its retrieval, but also its identification, because the role of the research subject is essential to have it make sense, implies defining and understanding its organization. This is one of the specialties of IS researchers. It has a historical background, a journal (Knowledge Organization), a scientific society (ISKO), and an undeniable international recognition within the field of IS. In France, it has also developed, and the organization of regular conferences by the French Chapter of ISKO gives visibility to this research area that has so little space in French journals.

We feel that to move forward on the proposal of establishing a tight link with scientific communication, we should aim at conducting works proposed by Yolla Polity in 1999 (Polity 1999) in a pluridisciplinary perspective. We must state here that in the recent past, at least three authors, who, for reasons of their own, did not institutionally join our discipline, E. de Grolier, J.C. Gardin, and R. Pagès, ${ }^{2}$ have conducted projects that had a significant impact in the field. The last two have shed light on knowledge organization problems in the field of archeology ${ }^{3}$ and psychology. Polity proposes a chronology of French works: the 1970s, influenced by the expansion of document processing technology; the 1980s, oriented more towards natural language processing; and the 1990s, with the development of hypertext, interfaces, and neuronal networks. The recommended perspectives of "revisiting our cultural heritage in order to extract what topics remain and to build a shared conceptual body" and work on an "update of the domain modelization" (Polity 1999, 375) still seems relevant today.

We would like, eleven years later, to bring our contribution to this "state of affairs," putting the emphasis not as much on the multidisciplinarity of the discipline, but rather on its intradisciplinarity. We agree with the idea that it is necessary to evaluate French scientific research because it appears, to us, in line with the wish expressed by Polity that this is a way "to allow the French research community to occupy a major position within the international research community" (Polity 1999, 375), and we also add the occupation of an original space that would ensure the link between information and communication.

Research that aims at highlighting roles other than those through which languages are generally analyzed is still little developed. The object is not to study the languages for themselves, but to transfer the focus towards their implication into a planned or induced communication. They then become material for observation. However, successfully conducting such investigations requires a good knowledge of these lan- guages, of the way they work, are built, and used. We propose to illustrate the possibilities offered by this approach through three examples of projects conducted by our research team in Toulouse, some being centered on an institutional and epistemological preoccupation, others on the construction of stereotypes, and then on informational culture.

\section{Knowledge organization and communication processes}

\subsection{Institutionalization of a discipline}

Starting with the idea that the institutionalization of a discipline goes through different phases and that it can be constantly challenged, a research project (Couzinet 2008) was conducted on a set of tools (classification schemes, bibliographies, databanks, book reeditions), elaborated in a professional field, that may contribute to the institutionalization process. The observation "ground" was that of information and communication sciences, and each version of the analyzed languages was anchored in a period going from 1970 to 1990.

The first phase is administrative. It refers to the agreement obtained at the highest state level, but it can only be consolidated if researchers make the works that they mean to develop visible. A second phase is then proposed that focuses on the interest of building a representation of the discipline. Languages are not, then, the only materials used. The approach is founded on the model developed by Estivals, who observed the evolution of bibliology through the tables of contents of books and classifications. Classification is considered by this author as a specific methodology of theoretical bibliogy. It allows us to specify the object, the composition of the domain, and the theoretical perspectives under which phenomena can be studied. The classification scheme thus becomes a research scheme. Following this work, a classification of bibliology was elaborated by Estivals and Meyriat (Estivals 1993). It takes into account the French context and its inclusion into the field of ICS. It was followed by work that aimed at elaborating the Thesaurus of bibliogy (Boustany and Estivals 1999), which made transversal links between sub domains and concepts visible. The two tools are intended to force delimitation and comparison with close disciplines and a reflection on the expression of concepts. Their elaboration leads to a representation of the domains that the discipline means to cover and of the space it occupies or means to occupy. This epistemological work corresponds to an internal construction phase. 
V. Couzinet. Knowledge Organization in Information and Communication Sciences, a French Exception?

The extension of this work (Couzinet 2009) consisted in proposing a third phase, one of consolidation based on the representation of the discipline in libraries. The observation focused on the space occupied within the classification and lists of subject headings used in these cultural places to perceive how the public is affected by them. The classification system of university libraries, within the framework of student training, was then analyzed. It shows, through the proximity between subjects, the development of the domain, including work on objects mainly within the field of communication sciences. Finally, the French newspaper Le Monde thesaurus defines a different vision, that of daily news and that shared with a larger public. It also highlights the representation of the work of documentalists by journalists, also considered information professionals, as being oriented exclusively towards practice.

\subsection{The elaboration of stereotypes}

To extend a set of research projects dedicated to the elaboration of stereotypes through concrete documentary objects, such as journals and magazines, Caroline Courbières proceeded to the analysis of the concept "feminine" through documentary languages. Seen as a "reference discourse in knowledge representation, while belonging to the cultural horizon through which they arose and on the contexts of reception in which they are interpreted" (Courbières 2010, 150), they are mobilized as texts that follow the elaboration of meaning in identified contexts. Claiming a documentological approach, the author needs to shed some light on their meaning and state why and how, the main hypothesis being that through their characteristics, they represent "a particular stereotype that fixes the feminine in its linguistic representations."

The diachronic observation centers on abridged versions of classification schemes used during the second half of the 20th century (Dewey Decimal Classification, Universal Decimal Classification), and the UNESCO Thesaurus and RAMEAU $U^{4}$ authority file in their complete versions. The documentation centered on information processing is essentially semiological. It is then convenient for the analysis of the structure and concepts that make up its tools.

The documentary items show the image of a plural woman. Gender is the identity characteristic that includes the feminine concept in a second position through its sexual orientation. Sex as a practice is linked to the sphere of morality or law, but its value is reasserted in the mention of discrimination. However, the female sex is valued in the physiological domain through the notion of motherhood. The mother figure, in the social domain, refers to the single mother, the working mother, the housewife. Women's work is associated to the figure of the citizen. Thus what Courbières (2010, $175 \mathrm{ff}$.) calls "documentary woman" is at the meeting point between transgression and domestication, and we cannot develop all its facets in this context. This documentary woman is represented in an asymmetry that is extended through the mentions of father and mother in the social sphere. "Oscillating between clinical discourse, community claims and singular social roles, the documentary language reveals fixed representations of the feminine role, at the crossroads between the private and the public spheres" (Courbières 201, 242).

\subsection{Informational culture}

In research conducted through a set of projects with the objective of making the importance of the link between professors and documentalists explicit, to point out the double responsibility assumed in French secondary school documentation centers, there has been an attempt to establish a link between the documentation activity and the teaching activity. A corpus has been gathered from a set of classifications and thesauri, privileging not the actuality of language, but rather the originality of presentation and its environment of application. Starting from the main mission of teaching, that is to help the student become an independent adult, the analysis was also centered on the thesaurus of Le Monde newspaper, taken as an opening on current affairs, and the thesaurus of the Chamber of Commerce and Industry of Paris, called Synchronized System of Economic Documentation (DES), taken as an opening on all possible professional activities.

The privileged entry point in these analyses is the distinction established on the basis of the training of documentation teachers between "information culture," a generic name that we have proposed to use for the cultural fundamentals that each individual possesses or should possess, and "informational culture," a culture that is specific to the community of information professionals. The latter is based on skills and knowledge acquired during courses referring to the ICS discipline. It is a capacity to mobilize practice and theory in order to ensure the transmission of intellectual methodologies and a knowledge authorizing the exploitation or appropriation of information with a distanciated and critical view (Couzinet 2008b). 
The hierarchies and subject associations lead to an understanding of the meaning intended by the designer of the language. When a field of knowledge is not very familiar, it makes its approach simpler. However, the network of links is also an interpretation. A precise analysis of classification schemes underlines the fact that the main function of the tool is to manage a document collection, but it also has a communication function. This point of view, in the case of law, whose concepts are presented in the DES thesaurus so as to draw a balance, is particularly remarkable. Public and private law, which seem balanced, are situated on each side of an axis dominated by justice. If, in addition, we set business law as a foundation, the schema will carry a certain vision of Law. The use of colors, the arrangement of concepts, and the lines that link them mean that business surrounded by public law and private law may lead to justice (Couzinet 2011).

Using documentary languages to accomplish a technical task does not dissociate them from taking into account their operating and building modes, or from the context of the project underlying their elaboration. Training students to perceive the mediation that hybridizes itself through the project in order to facilitate information access, together with other projects made less perceptible by non-initiated, appears to us the main mission that justifies the union between documentation and teaching. In our opinion, it relies on the acquisition of an informational culture.

If we refer to the three major themes defined by Polity, these three examples show very uncommon ways, in France, to approach knowledge organization and its tools. They lie at the confluence of information and communication.

\section{A French exception?}

\subsection{Foreign research}

How is work on knowledge organization conducted abroad? We will not pretend to give an exhaustive answer to this question, which, on its own, would require extensive research. However, by referring to the synthesis proposed by Maria J. Lopez-Huertas, which is based on 151 references, and to articles from Birger Hjørland, we can perceive whether the approaches that we have isolated are present.

The most common research projects focus on the quality of knowledge organization systems, from the point of view of their content and also from the technical and technological standpoints. The key word in this way of tackling the subject is "interoperability."
The tendency is to reformulate the questions in a technological and interdisciplinary context (LopezHuertas 2008), what Hjørland (2003, 88) considers the "technology-driven phases." He isolates five of them: manual indexing and classification in libraries and benchmarking works that provide the principles of knowledge organization, which he considers still valid and important; documentation and scientific communication originating from the documentation movement founded by Otlet and Lafontaine; the recording and retrieval of information by computers since 1950; information retrieval through citations; and, finally, full text searching, hypertext, and internet searching since 1990.

This topic is not well supported theoretically and methodologically (Lopez-Huertas 2008; Hjørland 2003), it is rather made up of a superimposition of models and methodologies that are not really linked together. This is associated with interdisciplinarity, which is not specific to our discipline, but which reveals itself to be tricky, because it is, in fact, fragile. It is specified that, facing concepts imported from somewhere else, it is necessary to build our own terminology because epistemological problems severely affect the activity of interdisciplines (Lopez-Huertas 2008).

Another research orientation concerns social organization of knowledge. This trend is supported by Hjørland and Albrechtsen who consider it necessary to develop approaches based on a more historical and cultural understanding. This is what they call domain analysis. Involved in complexity, so they seem to refer to Edgar Morin (1990) and suggest domain studies should consider the complex interaction of ontological, epistemological and sociological factors influencing the development of fields of knowledge (Hjørland and Hartel 2003). The journal Knowledge Organization has published works that belong to this approach, in the artistic or nursing domains, for example.

\subsection{French specificities}

Is it possible to consider that there is, as the French like to believe in numerous areas, a French exception in the way we approach the matter of knowledge organization? If we compare the chronology made by Polity with the division made by Hjørland, it is possible to consider that these elements come up together, even if the aim of the argument of the first differs from the second, going into less detail and precision. The technological concern is omnipresent. Both call for the development of a theory. 
The three research initiatives presented here could belong to the trend initiated by Hjørland, insofar as they take into account a social context and a knowledge domain and have a historical dimension ${ }^{5}$. However we also need to use our own knowledge of documentary languages, in the generic sense of the term, to highlight the processes that aim at influencing the users.

We consider that, by providing similar referents and ordering knowledge, languages produce and transmit a certain vision of the world. Within libraries, the ordering and presentation of documents, the signage, the address of each document recorded in the database, are repeated references facilitating the assimilation of an order. Some classification schemes are part of a project that surpasses the goal of document access. Gérard Régimbeau showed, for example, that in the artistic domain, document indexing contributed to the propagation of ideas (Régimbeau 1998). Similarly, classification schemes used in the USSR or China participated in the diffusion of a certain conception of collective life.

The power of suggestion of knowledge organization combines ideal elements that are often indispensable with practical information, in a constant interaction between a given situation and the individual. They induce a certain kind of behaviour, but also a way of thinking that provokes support for a project. As far as we know, the social approach promoted by Hjørland and Albrechtsen has not yet reached the communication sphere, but the first works in this trend tend to meet Meyriat's and our own work.

\subsection{About some exceptions}

It is often admitted by French information and communication sciences researchers that the combination of these two disciplines-information science and communication science, and even other disciplines, such as cultural studies, media studies, museology-is an exception on the international scene. We agree with this, but we do not belong to those researchers who think this position has no scientific justification. The work conducted by discipline pioneers to precisely determine the limits of this exception clearly reveals that they can be imbricated. Specifying outlines is equal to defining research programmes.

If, historically, our discipline has left aside this fundamental exercise to ensure its perennity, studying its organization opens research perspectives at intersections. Thus knowledge organization can be thought of as (Hjørland 2008, 86):
Activities such as document description, indexing and classification performed in libraries, bibliographical databases, archives and other kinds of "memory institutions" by librarians, archivists, information specialists, subject specialists, as well as by computer algorithms and laymen. $\mathrm{KO}$ as a field of study is concerned with the nature and quality of such knowledge organizing processes (KOP) as well as the knowledge organizing systems (KOS) used to organize documents, document representations, works and concepts ... In the broader meaning $\mathrm{KO}$ is about the social division of mental labor, i.e. the organization of universities and other institutions for research and higher education, the structure of disciplines and professions, the social organization of media, the production and dissemination of "knowledge" etc.

It can also be considered as the most convenient material to reveal social dimensions belonging to scientific, political, pedagogical or cultural communication. As such, it is not the privileged domain of information science. The complexity of its elaboration and its use as an indexing tool induces the capacity to analyze it as such. It is then one of the meeting points between information and communication, an intradisciplinary link.

Thus it is possible to question the plural form used in France, another exception, to name the discipline that studies it. Meyriat considers that the plural applies to press studies and the singular to documentation (Meyriat 1986). For Jacques Maniez, Information Sciences are "open to different aspects of this social phenomenon, whereas Information Science is wholly dedicated to theoretical and practical document matters, similarly to its English homologue" (Maniez 2002, 41). Multiplying research projects involving information and communication is part of the efforts made towards collective elaboration of the disciplinary project. The classification announced by J. Meyriat implies a reflection on an information-communication science, singular and autonomous, built around the link between significant and signified of an acquired and recognized maturity.

\subsection{Conclusion}

French researchers approach the theme of knowledge organization in a way that does not seem very different from foreign research. As in foreign research, technique and technologies play significant roles. Not 
very welcomed in the French journals, and handicapped by language for its international circulation, its particularity is that it is not widely broadcasted. The ISKO conferences are, in this respect, very important.

Knowledge organization also suffers from its interdisciplinarity, which deprives it of methodologies, theories, and concepts of its own. Its position at the heart of a discipline that is, itself, an interdiscipline seems to authorize it not to consider its own fundamentals together with common theoretical foundations. The contribution of the ISKO journal, as a medium through which the international dimension of our research field is elaborated, is vital. However, it also is necessary to be concerned with the opening of French journals to this research topic in order to avoid isolation and to build the info-communicational approach of knowledge organization collectively.

\section{Notes}

1. SOFRASIC is the former name of the French Society for Information and Communication Sciences (SFSIC).

2. Eric de Grolier worked with J. Meyriat at UNESCO. Jean-Claude Gardin is the founder of the Synthol documentary language and Robert Pagès of the Codoc.

3. More recently, we can add René Ginouvès and Anne-Marie Guimier-Sorbets.

4. Encyclopedic Alphabetical and Unified Directory of Subject Authorities.

5. We do not claim that the domains are exclusive, as the following works may show: Olson Hope A. and Ward, D.B. 1998. Charting a journey across knowledge domains: feminism in the Dewey Decimal Classification. In Mustafa el Hadi, W., Maniez, J. and Pollitt, S.a. eds., Structures and relations in knowledge organization: Proceedings of the Fifth International ISKO Conference (Lille, France, August 25-29, 1998). Advances in knowledge organization, no. 6. Würzburg: Ergon., pp. 238-44.

\section{References}

Boustany, Journana and Estivals, Robert Paris. 1999. Thésaurus de la bibliologie. Paris : Société de schématologie et de bibliologie.

Courbieres, Caroline. 2010. Femme en contextes: la conception stéréotypée du féminin au travers du langage documentaire (1958-2008). Mémoire d'habilitation à diriger des recherches en sciences de l'information et de la communication, Université de Toulouse (France).

Couzinet, Viviane. 2001. Jean Meyriat, théoricien et praticien de l'information-documentation. Paris: ADBS.

Couzinet, Viviane. 2011. Janus ou le langage documentaire: union des deux faces d'un métier. In Frabre, Isabelle, ed., Professeur documentaliste: un tiers métier. Dijon: Educagri, pp. 173-90.

Couzinet, Viviane. 2009. Transmitir, difundir: formas de institucionalizaçao de uma disciplina. Perspectivas em ciencia da informaçao $14 \mathrm{n}^{\circ}$ sp.: 5-18.

Couzinet, Viviane. 2008a. Représenter, répertorier, transmettre: formes d'institutionnalisation d'une discipline. In Marteleto, Regina Maria and Thiesen, I. eds., Médiations et usages des savoirs et de l'information: un dialogue France-Brésil, $1^{\text {er }}$ colloque du réseau MUSSI, Rio de Janeiro, 4-7 novembre 2008. Rio de Janeiro: MUSSI, pp. 63-81.

Couzinet, Viviane. 2008b. Vers "une société du savoir": approche ethno-informationnelle de la "culture de l'information", Annalele stintifice ale universitatii Alexandru Ioan, tom.1, p. 83-98.

Estivals, Robert Paris. 1993. Classification de la bibliologie. In Estivals, R, ed., Les sciences de l'écrit: encyclopédie internationale de bibliologie. Paris: Retz, pp. 112-19.

Hjørland, Birger. 2008. What is knowledge organization . Knowledge organization 30: 86-101.

Hjørland, Birger. 2003. Fundamentals of knowledge organization. Knowledge organization 35: 87-111.

Hjørland, Birger, and Albrechtsen, Hanne. 1995. Toward a new horizon in information science: domain- analysis. Journal of the American Society for Information Science 46: 400-25.

Hjørland, Birger, and Hartel, Jenna. 2003. Introduction to a special issue on domain analysis. Knowledge organization 30: 125-27.

López-Huertas, Maria-José. 2008. Some current research questions in the field of knowledge organization. Knowledge organization 35: 113-36.

Maniez, Jacques. 2002. Actualité des langages documentaire: fondements théoriques de la recherche d'information. Paris: ADBS.

Meyriat, Jean. 1986. La science de l'information. Revue des sciences morales et politiques n²: 255-69.

Meyriat, Jean. 1983. Pour une classification des sciences de l'information et de la communication. Schéma et schématisation n ${ }^{\circ}$ 19: 61-64.

Meyriat, Jean. 1980. Social science information languages: a comparative analysis. International classification 7: 60-65. 
V. Couzinet. Knowledge Organization in Information and Communication Sciences, a French Exception?

Morin, Edgard. 1990. Introduction à la pensée complexe. Paris: le Seuil.

Polity Yolla. 1999. L'organisation des connaissances en France: état des lieux. In Maniez, J. and Mustafa El Hadi, W., eds., Organisation des connaissances en vue de leur intégration dans les systèmes de représentation et de recherche de l'information: $1^{\mathrm{er}}$ colloque du chapitre français de l'ISKO. Villeneuve d'Ascq: collection du Conseil scientifique de l’Université Charles de Gaulle, Lille 3, pp. 367-76. 